\title{
rRT-PCR Results of a Covid-19 Diagnosed Geriatric Patient
}

\author{
Özkan Görgülü ${ }^{1}$ (D) $\cdot$ Murat Duyan ${ }^{2}$ \\ Accepted: 13 October 2020 / Published online: 17 October 2020 \\ (C) Springer Nature Switzerland AG 2020
}

\begin{abstract}
In this study, we aimed to present a geriatric patient with the diagnosis of COVID-19 and with contradictory results in rRT-PCR examinations in short time intervals. A 69-year-old male patient was admitted to the emergency room on the 18th day of May 2020, with the complaints of fever, sweating, myalgia, dry cough that continued for 5 days, and the lack of taste that started on the day he applied to the emergency room. Comorbidity factors include diabetes mellitus, bronchial asthma, and hypertension. The patient has a history of 36 years of smoking 1.5 packs per day. High laboratory findings during hospitalization: monocytes, creatinine, CRP (C-reactive protein). In the thorax CT, in the parenchyma areas of both lungs, there are increases in attenuation with multilobe distributions (more visible at the level of the upper lobes) in the form of ground-glass opacities. May 19, 2020, was subjected to the rRT-PCR test, repeated twice on the 19th of May which also resulted in positive. Despite rRT-PCR tests, which were negative on 27th of May and positive on 28th of May, the patient, whose symptoms disappeared, and general condition improved, was discharged on June 1, 2020, with the recommendation for home isolation. In our case, unlike the incubation period only, we encountered a negative rRT-PCR result on the 8th day after diagnosis. Therefore, the COVID-19 pandemic control and filiation evaluation with the rRT-PCR test may produce false negative results.
\end{abstract}

Keywords COVID-19 $\cdot$ SARS-CoV-2 $\cdot$ Geriatrics $\cdot$ Reverse transcriptase polymerase chain reaction $\cdot$ Tomography $\cdot$ Mass screening $\cdot$ False negative reactions

\section{Introduction}

Coronavirus disease 2019 (COVID-19), also known as severe acute respiratory syndrome coronavirus 2 (SARS$\mathrm{CoV}-2$ ), is a new zoonotic infectious disease which was first reported to the World Health Organization on 31 December 2019, and which was declared as a pandemic by the WHO on March 11, 2020 [1]. COVID-19 continues to affect elderly adults disproportionately with severe patient losses, from severe hospitalization to

This article is part of the Topical Collection on Covid-19

Özkan Görgülü

drozkangorgulu@hotmail.com

Murat Duyan

drmuratduyan@gmail.com

1 Department of Anesthesiology and Reanimation, Antalya Training and Research Hospital, Varlık Mh. Kazım Karabekir Cd, 07100 Antalya, Turkey

2 Department of Emergency Medicine, Antalya Training and Research Hospital, Antalya, Turkey increased risk of mortality [2]. Advances in various diagnostic approaches such as real-time polymerase chain reaction (rRT-PCR), chest radiography and computed tomography (CT) imaging, and other modern diagnostic methods for this infection have been emphasized as the major diagnostic tools [3]. rRT-PCR is the preferred method for measuring mRNA [4]. Definite diagnosis of COVID-19 is based on the viral isolation or positive result of polymerase chain reaction from sputum, or throat swab, or nasal swab [5]. Although rRT-PCR is often described as a "gold" standard, it is far from being a standard assay [4]. In this study, we aimed to present a geriatric patient with the diagnosis of COVID-19 and with contradictory results in rRT-PCR examinations in short time intervals.

\section{Case Report}

A 69-year-old male patient was admitted to the emergency room on the 18th day of May 2020, with the complaints of fever, sweating, myalgia, dry cough that continued for 5 days, and the lack of taste that started on the day he applied to the 
emergency room. Comorbidity factors include diabetes mellitus, bronchial asthma, and hypertension. The patient has a history of 36 years of smoking 1.5 packs per day, which lasted from 12 to 48 years old. The patient, who weighed $138 \mathrm{~kg}$ prior to the pandemic and was $1.74 \mathrm{~m}$ tall, now weighs $129 \mathrm{~kg}$. In the emergency room, the temperature of the patient was $37.5^{\circ} \mathrm{C}, \mathrm{SpO}_{2}$ was 96 , pulse was 93 , noninvasive blood pressure arterial was $135 / 70$, and blood sugar measurement from the finger was $140 \mathrm{mg} / \mathrm{dL}$. The laboratory findings were leukocyte $7.910^{3} / \mathrm{mm}^{3}$ (4-10.5), neutrophils $4.710^{3} / \mathrm{mm}^{3}$ (1.82-7.42), lymphocyte $2.210^{3} / \mathrm{mm}^{3}(0.85-3)$, monocytes $0.910^{3} / \mathrm{mm}^{3}$ (0.19-0.77), platelets $277.010^{3} / \mathrm{mm}^{3} 150-450$, blood urea nitrogen $30 \mathrm{mg} / \mathrm{dL}$ (8-20), creatinine $1.76 \mathrm{mg} / \mathrm{dL}$ (0.81-1.44), ALT $50 \mathrm{U} / \mathrm{L}$, AST $46 \mathrm{U} / \mathrm{L}$, GGT $38 \mathrm{U} / \mathrm{L}, \mathrm{LDH}$ $303 \mathrm{U} / \mathrm{L}$ (<248), CRP $80.8 \mathrm{mg} / \mathrm{L}(0-5)$, D-dimer $223 \mu \mathrm{g} / \mathrm{L}$ (0-242), and sedimentation $1 \mathrm{~h} 18 \mathrm{~mm} / \mathrm{h}(0-20)$.

In thorax CT of the patient, in the parenchyma areas of both lungs, there are increases in attenuation with multilobe distributions (more visible at the level of the upper lobes) in the form of ground-glass opacities (Fig. 1).

In the COVID-19 Pandemic Clinic, following the pantoprazole $1 \times 40 \mathrm{mg}$, hydroxychloroquine sulfate $(200 \mathrm{mg})$ after $2 \times 400$-mg loading dose, $2 \times 200$-mg maintenance dose, oseltamivir $2 \times$ $200 \mathrm{mg}$, vitamin C (ascorbic acid) $500 \mathrm{mg} / 5 \mathrm{~mL}$, Oksapar 6000 ANTI-XA IU/0.6 mL, and Beklomethasone dipropionate, salbutamol $100 \mathrm{mcg}$ inhaler was administered.

In the patient with palpitations 2 days following the hospitalization, ECG: supra ventricular tachycardia (137/ $\mathrm{min})$, left bundle branch echocardiography: Ejection fraction $60 \%$, left ventricular concentric hypertrophy, diastolic dysfunction, and stage I left atrium dilatation were detected. By monitoring the patient, 6-mg intravenous bolus adenosine was administered. Due to ongoing supraventricular tachycardia, 12-mg adenosine intravenous bolus was repeated $10 \mathrm{~min}$ later. Through the intervention, the patient returned to sinus rhythm. Metoprolol $1 \times 50-\mathrm{mg}$, amlodipine $1 \times 10 \mathrm{mg}$, and adenosine $250 \mathrm{mg} / 50 \mathrm{~mL}$ intravenous infusion were added to the patient's treatment.

RT-PCR test the patient living in a low socioeconomically low area resulted as negative within the scope of filiation screening on April 21, 2020. Patient with positive Covid-19 IgM Rapid Test performed on May 19, 2020, was subjected to the rRT-PCR test, repeated twice on the 19th of May which also resulted in positive. Despite rRT-PCR tests, which were negative on 27 th of May and positive on 28th of May, the patient, whose symptoms disappeared, and general condition improved, was discharged on June 1, 2020, with the recommendation for home isolation. The results of the repeated rRTPCR test on June 15, 2020 were also negative (Fig. 2). The patient does not currently have any symptoms related to the disease.

\section{Discussion}

Although subfebrile fever and leukocytosis can usually be seen in viral infections, it is noteworthy that our patient had normal fever and leukocyte levels. In the literature, investigating COVID-19 pneumonia, increased CRP serum level, and lymphopenia are noted [6]. In our case, while neutrophil, lymphocyte, and platelet counts were at normal values, monocyte and CRP values exhibited increases.

Both lung and cardiovascular injuries are common in the management of COVID-19 infections, especially those with only cardiovascular disease symptoms [7].
Fig. 1 Thoracic CT image of ground-glass opacities in the lung

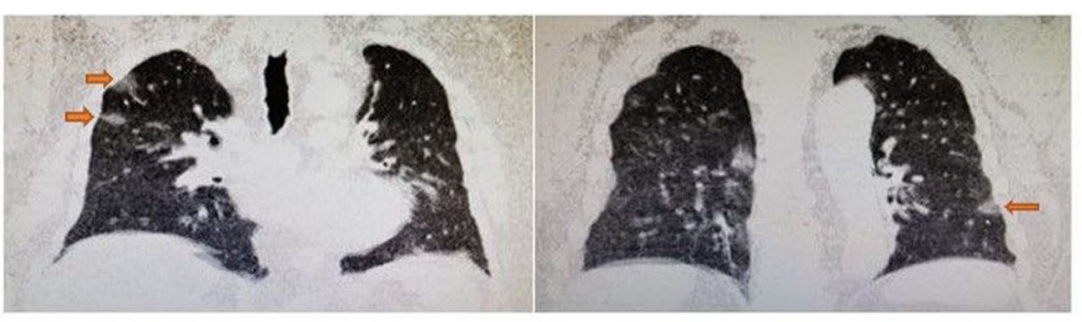

Coronal lung window

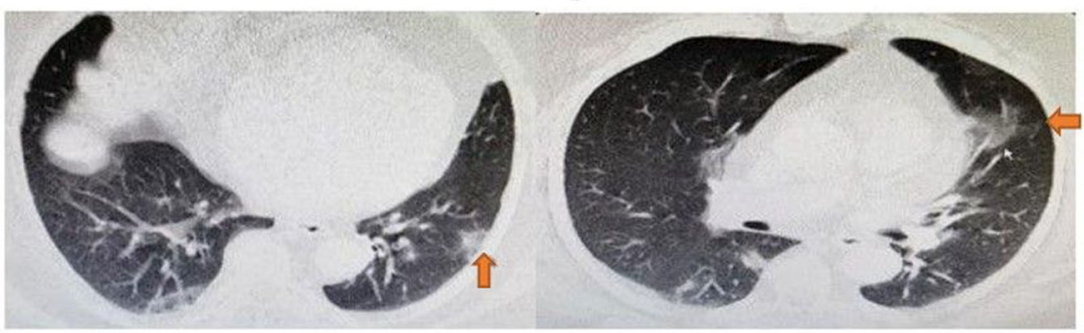

Axial lung window 
Fig. 2 rRT-PCR results of the geriatric patient

\begin{tabular}{|c|c|c|}
\hline $\begin{array}{l}15.06 .2020 \\
09: 37\end{array}$ & Covid 19 & NEGATIF \\
\hline $\begin{array}{l}28.05 .2020 \\
09: 34\end{array}$ & Cond 19 & POZITIF \\
\hline $\begin{array}{l}27.05: 2020 \\
11: 36\end{array}$ & Covid 19 & NEGATIF \\
\hline $\begin{array}{l}19.05 .2020 \\
08.01\end{array}$ & Covid 19 & POZITIF \\
\hline $\begin{array}{l}19.05 .2020 \\
08: 01\end{array}$ & Covid 19 & POzIIFF \\
\hline $\begin{array}{l}21,04.2020 \\
03.59\end{array}$ & Covid 19 & NEGATIF \\
\hline
\end{tabular}

Although a case of hydroxychloroquine-induced ventricular tachycardia has been reported in the literature [8], in our case, we could not determine the cause of supraventricular tachycardia since we also administered beta-agonist therapy together with hydroxychloroquine. Since our case has cardiac comorbidities, SARS-CoV-2 infection has been complicated to include the lungs. Morbidity and mortality of elderly patients with COVID-19 are higher than young and middle-aged patients [9]. In our case, intensive care and mechanical ventilation support were not required during the hospitalization process.

rRT-PCR results are just a momentary display of information about a specific amount of transcripts in a cell or tissue [4]. The nucleic acid test functions as the gold standard method for confirming the SARSCOV-2 infection; however, some recent studies have detected false negative results of real-time reverse transcriptase polymerase chain reaction (rRT-PCR) [4]. In the literature, $\mathrm{CT}$ sensitivity in the diagnosis of COVID-19 was determined as $97.2 \%$, while the initial rRT-PCR sensitivity was only $83.3 \%$ (10). However, rRT-PCR may initially give false negative results and it is suggested that rRT-PCR should be repeated for avoiding the isolation and misdiagnosis of patients with typical CT findings but negative rRT-PCR results [10]. False negative results increase especially during the incubation period of the disease. Similar to our case, there are case reports of reverse transcription-polymerase chain reaction (RT-PCR) test initially false negative and later positive in the literature [11]. Acquired immunity may protect against SARS-Cov-2 [12]. In contrast, in the case were reported that recovered from COVID19 pneumonia with positive serology, 6 negative nasopharyngeal rRT-PCR tests for 1 month and then a second IgM seroconversion and positive rRT-PCR test result after exposure to the virus [12]. In our case, unlike the incubation period only, we encountered a negative rRT-PCR result on the 8 th day after diagnosis. Therefore, it can be argued that COVID-19 pandemic control and filiation evaluation with the rRT-PCR test may produce false negative results.

Authors' Contribution Özkan Görgülü: Manuscript writing/editing. Murat Duyan: Data collection or management.

\section{Compliance with Ethical Standards}

Conflict of Interest The authors declare that they have no conflict of interest.

Financial Disclosure No financial disclosure was declared by the authors.

Ethical Approval Ethics committee approval is not required; data use permission was obtained from the hospital management.

Informed Consent Informed consent and publication permission of the patient was obtained.

Code Availability (Software Application or Custom Code) Available.

\section{References}

1. Mayr V, Nußbaumer-Streit B, Gartlehner G. Quarantine alone or in combination with other public health measures to control COVID19: A Rapid Review (Review). Gesundheitswesen. 2020.

2. Farrell TW, Francis L, Brown T, et al. Rationing limited health care resources in the COVID-19 era and beyond: ethical considerations regarding older adults. J Am Geriatr Soc. 2020;6.

3. Chakraborty C, Sharma AR, Sharma G, Bhattacharya M, Lee SS. SARS-CoV-2 causing pneumonia-associated respiratory disorder (COVID-19): diagnostic and proposed therapeutic options. Eur Rev Med Pharmacol Sci. 2020;24(7):4016-26. 
4. Nolan T, Hands RE, Bustin SA. Quantification of mRNA using real-time RT-PCR. Nat Protoc. 2006;1(3):1559-82.

5. Feng H, Liu Y, Lv M, Zhong J. A case report of COVID-19 with false negative RT-PCR test: necessity of chest CT. Jpn J Radiol. 2020;38(5):409-10.

6. Neveu S, Saab I, Dangeard S, Bennani S, Tordjman M, Chassagnon $\mathrm{G}$, et al. Incidental diagnosis of Covid-19 pneumonia on chest computed tomography. Diagn Interv Imaging. 2020;101(7-8):457-61.

7. $\mathrm{Li} \mathrm{G}, \mathrm{Hu} \mathrm{R}, \mathrm{Gu}$ X. A close-up on COVID-19 and cardiovascular diseases. Nutr Metab Cardiovasc Dis. 2020;30(7):1057-60.

8. Chen CY, Wang FL, Lin CC. Chronic hydroxychloroquine use associated with QT prolongation and refractory ventricular arrhythmia. Clin Toxicol (Phila). 2006;44(2):173-5.

9. Liu K, Chen Y, Lin R, Han K. Clinical features of COVID-19 in elderly patients: a comparison with young and middle-aged patients. J Inf Secur. 2020;80(6):e14-8
10. Long C, Xu H, Shen Q, Zhang X, Fan B, Wang C, et al. Diagnosis of the coronavirus disease (COVID-19): rRT-PCR or CT? Eur J Radiol. 2020;126:108961.

11. Balla M, Merugu GP, Pokal M, Gayam V, Adapa S, Naramala S, et al. A comprehensive approach is vital for diagnosing COVID-19: a case of false negative. J Clin Med Res. 2020;12(5):315-9.

12. Bentivegna E, Sentimentale A, Luciani M, et al. New IgM seroconversion and positive RT-PCR test after exposure to the virus in recovered COVID-19 patient. J Med Virol. 2020. https://doi.org/ 10.1002/jmv.26160.

Publisher's Note Springer Nature remains neutral with regard to jurisdictional claims in published maps and institutional affiliations. 